\title{
A nova teoria institucional em estudos organizacionais: uma abordagem crítica
}

\author{
The new institutional theory in organizational analysis: a critical approach
}

\author{
Alketa Peci *
}

\section{Resumo}

Nesse artigo apresento uma abordagem crítica do novo institucionalismo, destacando, principalmente, a incoerência interna dessa corrente atualmente dominante nos estudos organizacionais. Na primeira parte do artigo, faço um breve histórico do uso do conceito de instituição nos estudos sociais. Em seguida, analiso a contribuição do novo institucionalismo, mostrando as pesquisas de alguns dos principais representantes dessa linha de estudos. Segue-se uma análise crítica que evidencia, principalmente, as diferentes abordagens que caracterizam a escola, bem como sua incoerência em termos de níveis de análise e bases paradigmáticas. Na conclusão, argumento que o novo institucionalismo não pode ser considerado uma "escola" ou corrente consolidada de estudos organizacionais, uma vez que nele há pontos cruciais de divergência teórica, com implicações empíricas.

Palavras-chave: nova teoria institucional, paradigma, instituição

\begin{abstract}
In this paper I present a critical approach to the new institutional theory, highlighting the internal incoherence of this currently dominant perspective in organizational studies. In the first part of the paper, I narrate a brief historical perspective of the notion "institution" in social studies. I analyze the contribution of the new institutionalism, briefly presenting some important works of the main authors of this perspective. Follows the critical analyses that points out different approaches that characterize the new institutionalism and its incoherence in terms of levels of analyses and paradigmatic commitment. Finally, I argument that the new institutionalism can not be considered as a consolidated "school" in organizational studies, since there are still present crucial features of theoretical divergence, with clear empirical consequences.
\end{abstract}

Keywords: new institutional theory, paradigm, institution

\section{Introdução}

O principal objetivo deste artigo é analisar, a partir de uma abordagem crítica, a contribuição da nova escola institucional para os estudos organizacionais. Acredito tratar-se de uma corrente de estudos e pesquisas dominante na área desses estudos. Por isso, merece um olhar mais atento, voltado para a investigação das suas bases paradigmáticas, da sua coerência interna e das possibilidades que oferece em termos de pesquisas empíricas.

O novo institucionalismo será submetido ao que aqui denomino de crítica interna. Emprego as denominações "crítica interna" e "crítica externa" em referência ao posicionamento ante as premissas ontológicas e epistemológicas dos estudos organizacionais, sem que, no entanto, as proposições apresentadas sejam colocadas numa ou noutra categoria, uma vez que a intenção é fazer uso da idéia de continuum. A crítica interna diz respeito à crítica compartilhada com as premissas básicas de correntes dominantes dos estudos organizacionais, mas que ao perceber incoerências e inconsistências nessas análises, visa aperfeiçoar tais interpretações. Paralelamente, a

Doutora em Administração pela Escola Brasileira de Administração Pública e de Empresas da Fundação Getulio Vargas - EBAPE/FGV. Professora da EBAPE/FGV.. Endereço: Praia de Botafogo, 190 - sala 522 - Rio de Janeiro - RJ - Brasil - CEP 22253-900. E-mail: alketa@fgv.br 
crítica externa é o tipo de crítica que enfoca as próprias premissas das correntes dominantes nos estudos organizacionais, contribuindo para o pluralismo paradigmático da área.

Considerando o limitado espaço de um artigo, aqui apresentarei apenas a crítica interna à abordagem institucional. Outros estudos (PECI; VIEIRA, 2004) têm apresentado uma abordagem crítica que se aproxima do que aqui chamo de crítica externa, apontando incoerências na escola institucional, em termos das premissas básicas das correntes paradigmáticas que lhe servem de base.

\section{Instituição e institucionalismo: uma breve visão histórica}

O conceito de "instituição" vem sendo empregado há anos em estudos sociológicos e organizacionais. Entretanto, continua a ser um dos conceitos mais controversos em termos de concepção teórica e de aplicação prática. Everett Hughes foi um dos primeiros autores a empregá-lo. Para ele - que busca esse conceito na antropologia -, a única idéia comum a todas as utilizações do termo tem a ver com alguma forma de estabelecimento ou com a permanência relativa de alguma forma social distinta (HUGHES, 1936). Esse autor define a instituição como um empreendimento social implementado de maneira esperada e permanente (HUGHES, 1942, p.307); e, de fato, o estudo das instituições é o estudo da sociedade em ação, ainda que de uma ação que transcorre nos limites de formas sociais solidamente estabelecidas.

Os psicólogos tendem a ver as instituições como aspectos sociais do comportamento que eles tentam descrever, enquanto os sociólogos distinguem as instituições de unidades mais simples de comportamento social duradouro. Relacionando essas idéias ao conceito de comportamento coletivo -seres humanos se comportam em resposta ao comportamento dos outros; ou seja, o que o indivíduo faz pode ser compreendido usando a coletividade como ponto de referência -, o autor vê as instituições como fenômenos sociais. Nestes "a característica da permanência e aquela de comportamento coletivo se encontram de uma maneira particular, de modo que a própria forma assumida pelo comportamento coletivo é socialmente permanente.” (HUGHES, 1936, p.180).

A permanência das instituições decorre não apenas do fato de que estas satisfazem necessidades humanas destacando-se que essas necessidades são culturalmente definidas -, mas também de um conjunto de fatores contingenciais que nascem das relações inevitáveis "de fenômenos sociais com outros fenômenos sociais e com outros fenômenos que não são nada sociais." (HUGHES, 1936, p.181). Em sociedades civilizadas - caracterizadas pela mobilidade, isto é, a crescente elaboração de técnicas e máquinas para a produção e o aumento da quantidade e das opções de transportes e de comunicação -, a estrutura institucional das comunidades torna-se mais complexa. As instituições crescem em número e tornam-se mais especializadas em termos de função. Elas se sujeitam a um número maior de contingências, conseqüência do aumento da mobilidade.

Contudo, os primeiros estudos organizacionais adotam o conceito de instituição de um modo prescritivo, preocupados com as formas como uma organização pode tornar-se uma instituição; ou seja, ganhar legitimidade perante a sociedade e tornar-se permanente, sobrevivendo ao ambiente de negócios. Desenvolve-se, então, a chamada corrente de desenvolvimento institucional (ou institutional building), que causou grande impacto nos estudos organizacionais, especialmente, devido a seu caráter aplicado (PINTO, 1968, 1969).

Para Carvalho, Vieira e Lopes (2001), Philip Selznick é o precursor da abordagem institucional, ao interpretar as organizações como uma "'expressão estrutural da ação racional' que, ao longo do tempo, são sujeitas às pressões do ambiente social e transformam-se em sistemas orgânicos", passando por um processo de institucionalização através do qual "os valores substituem os fatores técnicos na determinação das tarefas organizativas." (CARVALHO, VIEIRA e LOPES, 2001, p.1). O novo e o velho institucionalismo compartilham o ceticismo perante o pressuposto do ator racional e enfocam a análise na relação das organizações com o seu ambiente, ampliando, contudo, os limites desse ambiente. 


\section{A contribuição do novo institucionalismo}

Embora relacionado com a tradição sociológica de Selznick, o novo institucionalismo pretende ser diferente, trazendo novas contribuições para o campo dos estudos organizacionais. Provavelmente, a principal diferença entre as duas escolas está na influência do construtivismo social, adotado como perspectiva oficial do novo institucionalismo. De fato, a etnometodologia (GARFINKEL, 1967) e o construtivismo social (BERGER e LUCKMANN, 2001) são considerados como microfundamentos oficiais da perspectiva institucional (POWELL e DiMAGGIO, 1990). Seus principais proponentes afirmam compartilhar uma visão da realidade como socialmente construída e concentram seus esforços, principalmente, na análise de organizações inseridas num setor, campo ou sociedade (FONSECA, 2003; VENTURA, 2004).

Enquanto as correntes tradicionais tomavam como objeto de estudo as organizações individuais e consideravam o ambiente como pano de fundo, a nova abordagem institucional entende as organizações individuais como consequiência desse ambiente (BONAZZI, 2000). Todavia, a visão de ambiente amplia-se, incluindo elementos simbólicos. Segundo Carvalho, Vieira e Lopes (2001, p.7), antes da contribuição institucional, "os ambientes eram variáveis formadas por elementos de dimensão fundamentalmente objetiva, como os recursos materiais, a tecnologia e o capital". Os autores afirmam que a proposta institucionalista sugere o acréscimo de um "sistema de crenças e de normas institucionalizadas" à visão do ambiente formado por "fluxos e intercâmbios técnicos".

Num dos artigos clássicos da corrente neo-institucional, Meyer e Rowan (1983) baseiam-se na premissa da existência da chamada sociedade pós-industrial, cujas estruturas organizacionais formais refletem os mitos dos contextos institucionais nos quais estão inseridas, em vez das demandas decorrentes de atividades do seu trabalho. Os autores, numa referência ao construtivismo social, concebem as organizações como reflexos estruturais da realidade socialmente construída, sendo condicionadas, principalmente, por seu ambiente institucional. Desse modo, o mito da racionalidade - expresso por meio de regras institucionais racionalizadas, presentes em diferentes domínios da atividade - influencia a forma e a expansão da organização formal que incorpora tais regras como elementos estruturais: quanto maior o grau de modernização da sociedade, maior a presença das estruturas racionalizadas em dados domínios e maior o número de domínios com estruturas racionalizadas.

Esses autores identificam três processos na origem de mitos institucionais racionalizadores: a elaboração de redes relacionais complexas, o grau de organização coletiva do ambiente/contexto e os esforços das lideranças das organizações locais. Assim, o isomorfismo com as instituições do ambiente tem consequiências cruciais para as organizações:

- elas incorporam elementos legitimados externamente, em vez de considerar a eficiência organizacional;

- empregam critérios de avaliação externos ou cerimoniais para definir o valor de elementos estruturais; e

- a dependência de instituições externamente fixas reduz a turbulência e mantém a estabilidade.

Considerando que as estruturas organizacionais são criadas - tornando-se mais elaboradas - com o crescimento de mitos institucionais e em contextos altamente institucionalizados; por outro lado, também devem atender às atividades práticas. Nesse sentido, uma solução estável é a manutenção da organização num estado de loosely coupled.

Alguns autores fazem uma distinção entre ambiente técnico e ambiente institucional. O ambiente técnico é definido como o domínio no qual "um produto ou serviço é trocado no mercado e as organizações são premiadas pelo controle eficiente e eficaz do processo de trabalho." (SCOTT apud CARVALHO, VIEIRA e LOPES, 2001, p.7). Já o ambiente institucional é caracterizado "pela elaboração de normas e exigências a que as organizações se devem conformar se querem obter apoio e legitimidade do ambiente." (SCOTT apud CARVALHO, VIEIRA e LOPES, 2001, p.7). 
Ao distinguir regras institucionalizadas de comportamentos sociais predominantes - levando em conta que as regras institucionalizadas são definidas com base em Berger e Luckmann (2001) como classificações construídas pela sociedade ou interpretações compartilhadas -, Meyer e Rowan (1983, p.1) salientam que:

Tais regras podem ser simplesmente tomadas como evidentes, ou podem ser sustentadas pela opinião pública ou pela força da lei. Instituições inevitavelmente envolvem obrigações normativas, mas freqüentemente entram na vida social, primeiramente, como fatos que devem ser considerados pelos atores. Institucionalização envolve o processo pelo qual processos sociais e obrigações passam a ter um status de regra no pensamento e na ação social (MEYER e ROWAN, 1983, p.2).

Isso significa que ao longo dos processos cognitivo (fatos a serem considerados pelos atores) e normativo (obrigações normativas) presentes na institucionalização, os autores reconhecem uma expressão do poder - na concepção prevalecente na teoria organizacional -; isto é, o poder como uma variável expressa diretamente pelo controle da lei ou da opinião pública. Basicamente, os institucionalistas privilegiam a dimensão cognitiva e normativa no estudo dos processos de institucionalização, abordando o poder (quando o fazem) de uma forma simplista.

O artigo de Powell e DiMaggio (1983) é considerado outro clássico da nova corrente institucional. Revisitando o conceito weberiano de burocratização, esses autores argumentam que as causas da burocratização e da racionalização têm se modificado e que, atualmente, esse processo ocorre menos como conseqüência da competição e mais como resultado de processos miméticos que tornam as organizações mais similares, sem torná-las necessariamente mais eficientes.

Powell e DiMaggio oferecem uma análise macroinstitucional de mudança estrutural (definida como isomorfismo) nas organizações. Em vez de teorizar sobre a diversidade organizacional, o foco da sua análise é a similaridade organizacional. Eles trabalham com base no conceito de "estruturação", desenvolvido por Giddens (1979, 1989) para sintetizar ação e estrutura na análise sociológica, deslocando, contudo, o nível de análise para as organizações. Na prática, considerando as organizações e a sociedade como sinônimos, os autores não apenas cometem uma falácia ecológica, como também reificam um fenômeno relativamente novo e relevante para as sociedades ocidentais (RAMOS, 1981), sem apresentar a mesma importância nas chamadas sociedades tradicionais.

O campo organizacional - uma área reconhecida da vida institucional que inclui fornecedores-chave, consumidores de recursos e produtos, agências reguladoras e outras organizações que produzem produtos ou serviços similares - é uma definição-chave que vai guiar a agenda empírica do novo institucionalismo, a partir da publicação do artigo de Powell e DiMaggio. Esse conceito é similar ao conceito de setor societal (MEYER e SCOTT, 1992), um setor que inclui todas as organizações de uma sociedade que oferecem um determinado tipo de produto ou serviço junto com o conjunto de organizações associadas: fornecedores, financiadores, reguladores e assim por diante.

Os autores objetivam explicar os processos de estruturação (ou definição institucional) de tais campos organizacionais. Estes existem à medida que são "institucionalmente" definidos; ou seja, são caracterizados por uma ampliação do grau de interação entre as organizações no campo, pela emergência de estruturas de dominação e padrões de coalizão, além de um maior conhecimento mútuo entre os participantes envolvidos no mesmo empreendimento (POWELL e DiMAGGIO, 1983, p.148).

Com essa definição, torna-se evidente o distanciamento da perspectiva neo-institucional do construtivismo social, uma vez que os processos de interação identificados abrangem a dimensão consciente, enquanto o construtivismo social representado por autores como Berger e Luckmann (2001) ou a etnometodologia de Garfinkel (1967) trabalham com a dimensão inconsciente. Contudo, os próprios autores reconhecem a ambigüidade do conceito, a ser melhorado com base em investigações empíricas.

Uma vez estruturado o campo organizacional, poderosas forças emergem e levam as organizações a se tornaram mais similares entre si. Essas forças relacionam-se com as definições institucionais das formas estruturais legítimas. As organizações que são influenciadas por seu ambiente institucional - via profissionalização e papel 
desempenhado pelas estruturas estatais - apresentam similitudes nas suas estruturas e processos, dentro de um mesmo ambiente institucional. Segundo Vieira, Carvalho e Silva (2002), essas similaridades, esse processo de homogeneização são definidos como isomorfismo. Trata-se de um processo limitador que força uma unidade da população a se parecer com outras unidades que estão diante do mesmo conjunto de condições ambientais. $\mathrm{O}$ isomorfismo é proposto como um conceito-chave para compreender a política e os ritos de muitas organizações modernas, num contexto pós-weberiano.

Powell e DiMaggio (1983) diferenciam dois tipos de isomorfismo: o competitivo - existente onde competição e mercado livre estão presentes (foco de análise da ecologia organizacional) - e o institucional (foco de análise dos autores). Eles descrevem três tipos de isomorfismo institucional: coercitivo, mimético e normativo. O primeiro resulta de pressões formais e informais (sentidos como a força, a persuasão, o convite a se juntar) exercidas por outras organizações das quais as organizações dependem e por expectativas culturais da sociedade. Fatores como ambiente legal, estados racionalizadores e outras grandes organizações racionais são apontados como fontes de pressão. As organizações se modelam, refletindo outras organizações, de forma não intencional por meio de transferência ou rotatividade de empregados - ou explicitamente - por meio de firmas de consultoria, organizações e associações industriais. A última fonte de mudança organizacional isomórfica é normativa e decorre principalmente da profissionalização. A legitimação de uma base cognitiva produzida por especialistas universitários e o crescimento e a elaboração de redes profissionais - que atravessam as organizações e em torno das quais novos modelos se difundem com rapidez - são duas fontes importantes de isomorfismo normativo.

Seguindo essa linha de argumento, parece natural concordar com a conclusão de Meyer de que seria fácil prever a organização da administração de uma nova nação emergente sem saber nada sobre a nação em si, uma vez que nações periféricas são muito mais isomórficas - em termos de reforma administrativa e padrão econômico - do que qualquer teoria sobre o sistema mundial de divisão econômica do trabalho poderia esperar (POWELL e DiMAGGIO, 1983). No entanto, tal afirmação não pode ser vista como construtivista, pois não são levadas em consideração as diferentes formações culturais expressas nos esforços de reforma administrativa e que vão diferenciar os processos de reforma.

É também uma consequiência natural do argumento dos autores terminarem o artigo lançando uma série de hipóteses a serem testadas em futuras pesquisas. O principal objetivo - ou o maior valor dessa perspectiva, como afirmam - é sua utilidade para previsão, outra pretensão que não existe no construtivismo social ou na etnometodologia.

O quadro 1, elaborado por Vieira (2000), tem como principal objetivo sintetizar as três principais linhas da nova escola institucional:

\section{Quadro 1}

Três pilares das instituições

\begin{tabular}{cccc}
\hline & Regulativo & Normativo & Cognitivo \\
\hline Bases da submissão & Diligência & Obrigação social & Pressuposto \\
\hline Mecanismos & Coercitivo & Normativo & Mimético \\
\hline Lógica & Instrumental & Apropriação & Ortodoxia \\
\hline \multirow{2}{*}{ Indicadores } & Regras, leis, sanções & $\begin{array}{c}\text { Certificação, } \\
\text { acreditação }\end{array}$ & $\begin{array}{c}\text { Prevalência, } \\
\text { isomorfismo }\end{array}$ \\
\hline \multirow{2}{*}{ Bases da legitimidade } & Sancionada & Governada & Sustentada \\
& legalmente & moralmente & culturalmente \\
\hline
\end{tabular}

Fonte: Vieira (2000), adaptado de Scott (1995).

Como se pode perceber, o institucionalismo negligencia a dimensão do poder, e quando a aborda, o faz a partir de uma perspectiva tradicional, enfatizando o aspecto regulativo. Os mecanismos de coerção enfatizados são "localizados" em regras, leis e sanções. 
Vale a pena destacar também outra corrente que faz parte do novo institucionalismo, mas que diferencia-se dos artigos anteriormente citados pelo diferente nível de análise. O artigo de Zucker (1977) marca uma forma distinta de lidar com a institucionalização e o conceito de instituição. A autora, baseada na perspectiva etnometodológica, investiga os efeitos da institucionalização na persistência cultural, por meio de três experimentos distintos, cada um focando três aspectos diferentes da persistência: a transmissão, a manutenção e a resistência às tentativas de mudança. Zucker (1977) considera que conhecimentos sociais institucionalizados existem como fatos e como parte da realidade objetiva, podendo ser transmitidos diretamente nessas bases. Indivíduos percebem atos institucionalizados como objetivos e exteriores; e embora tais atos sejam socialmente criados, funcionam como regras objetivas, porque sua origem social é ignorada.

O desenho da pesquisa tenta reproduzir uma situação na qual a institucionalização dos atos pode variar de alta para baixa. A situação autokinética, cujo efeito é uma ilusão visual, é escolhida para o experimento. Um grupo de 180 "objetos femininos" são usados, com 45 objetos participando em cada um dos três experimentos que reproduziram a condição de influência pessoal, de contexto organizacional e de escritório, cada um dos quais variando em termos de nível de institucionalização (de menor para maior).

Todas as predições são confirmadas. A transmissão é influenciada pelo grau de institucionalização. Quanto mais institucionalizado, maior a manutenção sem controle social direto. A resistência à mudança é maior quando a institucionalização é maior.

O estudo de Zucker (1977) marca uma linha que privilegia o nível micro de análise institucional, aquele que privilegia a interação interpessoal como foco de pesquisa. Recentemente, um dos estudos que podem ser destacados nessa mesma linha é o de Prochno (2003). O autor propõe um modelo que visa compreender as diferentes fases do processo de formação de rotinas organizacionais (ou rotinização) e considera o desenvolvimento de rotinas como um processo influenciado por características estruturais (impostas pela organização) e por padrões emergentes de interação entre os membros organizacionais.

\section{Teoria institucional - as múltiplas e diferentes abordagens}

Diferentes representantes do novo institucionalismo assumem perspectivas muito diversas em termos de microfundamentos de ação; perspectivas que, implícita ou explicitamente, variam do funcionalismo ao olhar mais etnometodológico. A falha que a escola apresenta em termos de microfundamento de ação é reconhecida pelos próprios Powell e DiMaggio (1990). Os autores apresentam a teoria de estruturação de Giddens como base da macroanálise institucional. Contudo, enfocando variáveis reificadas em campos organizacionais, eles ignoram os processos de institucionalização que deram vida a essas variáveis (instituições).

Autores como Zucker (1977) abrem outra linha de estudos institucionais, nos quais o nível micro de ação e uma visão mais processual da institucionalização são privilegiados. Também dividem o novo institucionalismo em dois campos diferenciados, em termos de nível da análise e de concepção da instituição, tornando mais explícitas as incoerências dessa corrente dos estudos organizacionais.

Num artigo intitulado "Teorias institucionais da organização", a autora reflete sobre as diferentes perspectivas do novo institucionalismo (ZUCKER, 1987). Ela identifica duas abordagens teóricas distintas que enfocam dois processos centrais diferentes:

- o contexto, como instituição, assume que o processo básico é a reprodução ou cópia de fatos sociais do sistema (ou setor) em nível organizacional; e

- a organização, como instituição, assume que o processo central é a geração (criação de novos elementos culturais) no nível organizacional, considerando a reprodução como consequiência, não causa, da institucionalização.

O quadro 2 resume essas duas abordagens teóricas - "Contexto como instituição" e "Organização como instituição" -, apontando as conseqüentes divergências que trazem para o campo. Além de diferenciá-las em termos 
de motivos para a institucionalização (reprodução versus geração), a autora aponta as divergências que nascem em termos de tratamento de:

- fontes da institucionalização - a primeira coluna enfoca a racionalização e o crescimento do Estado como fonte principal de institucionalização, enquanto a segunda coluna destaca o papel dos grupos intra e interorganizacionais;

- locus da institucionalização: no primeiro caso, situado fora da organização, relacionado com o Estado. No segundo caso, relativo aos processos internos organizacionais ou a organizações similares; e

- resultados - com a primeira abordagem apontando para a questão da desvinculação da parte técnica e a questão da conformidade organizacional com o ambiente institucional - que embora possa representar maiores chances de sobrevivência, resulta em ineficiência -, enquanto a segunda abordagem privilegia a estabilidade e visualiza a eficiência em termos de contingência relativa às diversas alternativas. 


\section{Quadro 2:}

\section{Pontos principais de divergência teórica no novo institucionalismo}

\begin{tabular}{ccc}
\hline Abordagem teórica & Contexto como instituição & Organização como instituição \\
\hline Motivo & Reprodução & Geração \\
\hline Fonte & Crescimento do Estado & $\begin{array}{c}\text { Grupos pequenos e imitação de } \\
\text { outras organizações }\end{array}$ \\
\hline Lócus & Fora da organização & Processos internos \\
\cline { 2 - 3 } & Relacionado com o Estado & Organizações similares \\
\hline Resultados & Desvinculação da parte técnica & Estabilidade \\
\cline { 2 - 3 } & Ineficiência & $\begin{array}{c}\text { Eficiência contingente em termos } \\
\text { de alternativas }\end{array}$
\end{tabular}

Fonte: Zucker (1987, p.445).

Na coluna "Contexto como instituição", os processos institucionais nascem da racionalização que estimula o crescimento do Estado, as instituições são invariavelmente externas à organização e relacionadas com o Estado e a institucionalização produz desvinculação das estruturas internas organizacionais e ineficiência relacionada à tarefa organizacional. O poder e os processos coercitivos são localizados no Estado ou na sociedade como um todo. Pela abordagem da "Organização como instituição", estas são importantes fontes de institucionalização de uma nova ação. Os elementos institucionais nascem principalmente de processos intergrupais e organizacionais; processos e estruturas organizacionais formais tendem a ser não apenas altamente institucionalizados, mas servem também como fonte de nova institucionalização, e a institucionalização aumenta a estabilidade, criando rotinas que melhoram a performance organizacional, a não ser quando alternativas mais eficientes são ignoradas. Para essa abordagem, a ordem institucional é negociável e emergente, nunca sistematicamente controlada.

Outro ponto a merecer especial atenção tem a ver com os múltiplos níveis de análise da teoria institucional (ou melhor, "das novas teorias institucionais"). O quadro 3 destaca os três níveis de análise que prevalecem na escola institucional, apontando o contexto de institucionalização, a abrangência da definição com a qual se trabalha empiricamente, a fonte primária de institucionalização e as problemáticas decorrentes de cada perspectiva. 


\section{Níveis de análise na teoria institucional}

\begin{tabular}{|c|c|c|c|}
\hline $\begin{array}{c}\text { Contexto da } \\
\text { institucionalização }\end{array}$ & Abrangência & $\begin{array}{l}\text { Fonte primária de } \\
\text { Institucionalização }\end{array}$ & Problemática \\
\hline Contexto institucional & $\begin{array}{l}\text { “posições políticas, programas } \\
\text { e procedimentos da moderna } \\
\text { organização [...] são } \\
\text { manifestações de poderosas } \\
\text { regras institucionais que } \\
\text { funcionam como mitos } \\
\text { altamente racionalizados” } \\
\text { (Meyer e Rowan, 1977, p.343) }\end{array}$ & Sistema mundial & $\begin{array}{l}\text { As organizações tornam-se } \\
\text { "audiência" passiva de } \\
\text { conhecimento } \\
\text { institucional, porque as } \\
\text { regras formam-se a partir } \\
\text { do Estado ou até do } \\
\text { sistema mundial }\end{array}$ \\
\hline Campo organizacional & $\begin{array}{l}\text { “Organizações que, em suma, } \\
\text { constituem um campo } \\
\text { reconhecido de vida } \\
\text { institucional” (DiMaggio e } \\
\text { Powell, 1983, p.148) }\end{array}$ & $\begin{array}{l}\text { Redes } \\
\text { interorganizacionais }\end{array}$ & $\begin{array}{l}\text { Embora a maioria das } \\
\text { relações possam ser } \\
\text { estabelecidas entre as } \\
\text { organizações do mesmo } \\
\text { "campo", a } \\
\text { institucionalização pode } \\
\text { transcender as fronteiras de } \\
\text { um único campo }\end{array}$ \\
\hline $\begin{array}{l}\text { Estrutura interna da } \\
\text { organização }\end{array}$ & $\begin{array}{l}\text { Organização isolada, às vezes, } \\
\text { redes interorganizacionais }\end{array}$ & $\begin{array}{l}\text { Indivíduos interagindo } \\
\text { nas organizações }\end{array}$ & $\begin{array}{l}\text { Não consegue estabelecer } \\
\text { um esquema teórico } \\
\text { coerente, que possa levar } \\
\text { em consideração o } \\
\text { ambiente institucional }\end{array}$ \\
\hline
\end{tabular}

Fonte: adaptado de Zucker (1987).

Além da problemática da incoerência paradigmática e dos níveis de análise destacados anteriormente, o novo institucionalismo apresenta outros pontos de estrangulamento.

Para Hasselbladh e Kallinikos (2000) existe uma dissonância entre o status inovador de algumas idéias teóricas do novo institucionalismo e o caráter convencional do programa empírico associado a essa corrente. A agenda empírica do novo institucionalismo tem enfatizado, principalmente, o isomorfismo estrutural entre firmas e organizações públicas em sociedades modernas como um aspecto do processo de burocratização. $\mathrm{O}$ isomorfismo estrutural tem a ver com a emergência e a difusão de formas organizacionais similares ou aspectos estruturais similares da organização formal numa população de organizações, sem se diferenciar substancialmente de outras pesquisas que enfocam processos de difusão, em geral.

Na prática, o novo institucionalismo não consegue se distanciar da ortodoxia funcionalista dos estudos organizacionais. Como Hasselbladh e Kallinikos (2000) apontam, a questão da legitimidade - como referência da formação e difusão de padrões específicos de racionalização - é vista como requisito para a sobrevivência e o sucesso organizacional, sem representar, assim, um verdadeiro distanciamento da concepção tradicional adaptativa e funcionalista das organizações. Vale a pena lembrar que a base conceitual funcionalista de Parson já destacava que os sistemas se adaptam a valores e normas mais abrangentes. O enfoque prescritivo da análise organizacional continua a prevalecer. 


\section{Conclusões}

O principal objetivo deste artigo foi apresentar uma crítica ao novo institucionalismo, apontando, especificamente, alguns pontos de incoerência teórica e empírica que o caracterizam. A relevância desta reflexão justifica-se pelo fato de que, atualmente, o novo institucionalismo tem se apresentado com força na área de estudos organizacionais, desencadeando um amplo movimento "mimético" (usando a expressão da própria escola!), incentivado por uma postura pouco crítica e até limitante em termos de outras opções teóricas que possam contribuir para o tão desejado pluralismo paradigmático da área.

No entanto, acredito que criticar o novo institucionalismo com base em sua predominância na área de estudos organizacionais é irrelevante. Argumento, neste artigo, que a crítica deve buscar a consolidação de bases coerentes que possam incentivar a contribuição teórica e empírica dos pesquisadores da área de estudos organizacionais. Apontar incoerências internas, problemáticas e pontos de estrangulamentos numa escola ou corrente de estudos tem como objetivo incentivar uma adesão mais "consciente" a uma ou outra corrente - para os que sentem a necessidade de pertencer a "espaços científicos demarcados." (PECI \& ALCADIPANI, 2004).

Adiante, destaco algumas das lacunas que identifiquei na análise do novo institucionalismo, relativas ao que denomino de "confusão paradigmática" da corrente:

- a ausência de um microfundamento coerente de ação dificulta a compreensão dos pressupostos paradigmáticos dessa abordagem. A maioria das pesquisas da escola institucional são orientadas por uma perspectiva macro de análise (continuando a considerar o construtivismo social - com foco no nível micro - como paradigma base);

- embora predomine o nível de análise macro, o novo institucionalismo apresenta o problema da falácia ecológica, uma vez que perspectivas teóricas e empíricas que se autodenominam neo-institucionais privilegiam diferentes focos de análise, sem, no entanto, oferecer um quadro conceitual que possa estabelecer as inter-relações necessárias entre esses níveis de análise. As pesquisas de Zucker (1977) e Prochno (2003) se diferenciam, substancialmente, das predominantes macroanálises institucionais. Essas pesquisas apresentam um nível de coerência adequado ao construtivismo social e à etnometodologia, mas, divergem, substancialmente, do resto da literatura neo-institucional;

- a agenda empírica do novo institucionalismo é caracterizada pelo foco de pesquisa nos chamados processos de estruturação de campo ou setor organizacional, definido como reconhecida área de vida institucional que inclui fornecedores-chave, consumidores de recursos e produtos, agências reguladoras e outras organizações que produzem produtos ou serviços similares (POWELL e DiMAGGIO, 1983). Assim como o chamado "velho institucionalismo" considerava a organização uma unidade autônoma, os pesquisadores neo-institucionais consideram esses setores (ou campos organizacionais) como autônomos, reconhecendo apenas o caráter dependente de recursos, como organizações e pessoas. $\mathrm{O}$ foco no campo organizacional ainda demonstra uma visão reducionista do escopo de análise do construtivismo social (BERGER e LUCKMANN, 2001), cujo centro da análise escapa às fronteiras arbitrariamente estabelecidas por estudiosos das organizações, no caso específico, em torno de um campo ou setor;

De fato, acredito que as falhas e lacunas identificadas na escola institucional resultam, principalmente, dessa confusão paradigmática verificada nessa corrente dominante nos estudos organizacionais. Como já foi destacado, embora o construtivismo social e a etnometodologia sejam apresentadas como paradigmas oficiais do novo institucionalismo, a agenda empírica nem sempre segue esse compromisso paradigmático. O novo institucionalismo, contudo, apresenta outros pontos de estrangulamento:

- em termos empíricos, o novo institucionalismo considera as instituições como dadas e demonstra pouco interesse em termos de compreensão dos processos de institucionalização. Não questiona o porquê de determinadas práticas institucionalizarem-se e outras não;

- novo institucionalismo enfoca, principalmente, determinado tipo de mudança, em geral, relacionada aos processos isomórficos. A perspectiva não responde a questões como o porquê e de que maneira a 
emergência e a transformação ocorrem. Abbot (apud COLIGNON, 1997, p.15) argumenta que uma teoria tão relacionada com a reprodução tem dificuldades para atender questões de criação e transformação. De fato, o foco do novo institucionalismo está na durabilidade e na persistência das instituições. Por isso, seus resultados empíricos têm superestimado aspectos como o mimetismo organizacional (POWELL e DiMAGGIO, 1983; 1990);

- dessa perspectiva em vigor prevalece a visão que considera as organizações como categorias fixadas, essencialistas, pré-políticas e singulares (COLIGNON, 1997). As organizações assumem um status analítico privilegiado e tornam-se merecedoras de um foco de análise específico. Como o autor alerta, o essencialismo da análise organizacional serve para velar algumas pressuposições metodológicas tácitas. Por exemplo, o processo de criação de todas as organizações é considerado igual; as características essenciais das organizações são consideradas as mesmas. Desde a obra clássica de Selznick, o autor nos alerta, as organizações têm sido definidas como autônomas, apolíticas, associais e a-históricas (COLIGNON, 1997, p.2). Paralelamente, em muitos casos, as organizações são tratadas como sinônimo de instituições. Sem dúvida, as organizações, concebidas genericamente, são instituições. No entanto, a sua existência não pode ser considerada um ponto de partida para a análise institucional, mas um ponto de questionamento e investigação, até para melhor compreendermos as formas substantivas que elas assumem em campos organizacionais concretos (biotecnologia, energia, educação e outros). Isso requer reconfigurá-las, não a partir de (pré)suposições sobre a lógica que as governa, mas a partir das dimensões temporal, espacial e relacional;

- poder é uma dimensão ignorada - ou tratada a partir de uma perspectiva tradicional - na abordagem teórica e empírica da escola institucional. É enfatizado o aspecto regulativo do poder, não diferenciando-se a escola institucional de outras abordagens funcionalistas.

Basicamente, acredito que o novo institucionalismo é uma corrente pouco preocupada em termos teóricos e empíricos com processos de mudança e transformação organizacional e institucional. O negligenciar e/ou subdimensionar o poder pode influir no interesse relativo ao status quo. A incorporação do poder na análise, a partir de visões mais dinâmicas como aquelas advogadas por Foucault (1979) ou Bourdieu (VIEIRA e MISOCZKY, 2000), pode contribuir para a compreensão dos fenômenos de mudança e transformação.

Uma das reflexões principais deste artigo é que, nesse estágio de desenvolvimento do novo institucionalismo, acredito ser impossível referir-se a uma nova escola. Isso, principalmente, devido a essa confusão paradigmática que o caracteriza, traduzida na oscilação presente nos níveis de análise que guiam a reflexão teórica e as pesquisas empíricas. 


\section{Referências}

BERGER, P. L.; LUCKMANN, T. A construção social da realidade. 20. ed. Petrópolis: Vozes, 2001.

BONAZZI, G. Storia del pensiero organizzativo. Collana di sociologia. Milano, Italia: Franco Agneli, 2000.

CARVALHO, C. A. P. ; VIEIRA, M. F. V.; LOPES, F. The structuring of the organizational field of theaters and museums in the south of Brazil. In: EUROPEAN GROUP FOR ORGANIZATION STUDIES COLLOQUIUM (EGOS) XVII, 2001, Lyon. Anais... France, 2001.

COLIGNON, R. A. Power plays: critical events in the institutionalization of the Tennessee Valley Authority. Albany, NY: State University of New York, 1997.

FONSECA, V. S. da. A abordagem institucional nos estudos organizacionais: bases conceituais e desenvolvimentos contemporâneos. In VIEIRA, M. M. F.; CARVALHO, C. A. (Org.). Organizações, instituições e poder no Brasil. Rio de Janeiro: Editora FGV, 2003.

FOUCAULT, M. Discipline and punish: the birth of the prison. New York: Vintage Books, 1979.

GARFINKEL, H. Studies in ethnometodology. Englewood Cliffs, NJ: Prentice-Hall Inc., 1967.

GIDDENS, A. Central problems in social theory. Action, structure and contradiction in social analysis. Berkeley; Los Angeles: University of California Press, 1979.

Social theory and modern sociology. Stanford, CA: Stanford University Press, 1989.

HASSELBLADH, H.; KALLINIKOS, J. The project of rationalization: a critique and reappraisal of neo-institutionalism in organization studies. Organization Studies, v.21, n.4, p.697-720, 2000.

HUGHES, E. C. The ecological aspect of institutions. American Sociological Review, v.1, n.2, p.180-189, Apr. 1936.

The study of institutions. Social Forces, v.20, n.3, p.307-310, Mar.1942.

MEYER, J. W.; ROWAN, B. Institutionalized organizations: formal structure as myth and ceremony. American Journal of Sociology, n.2, p.340-63, 1983.

; SCOT, W. R. Organizational environments. Ritual and rationality. London: Sage Publications, 1992.

PECI, A.; VIEIRA, M. M. F. A construção do real e práticas discursivas: integrando a dimensão do poder nos processos de institucionaliz(ação). In: ENANPAD, 28., 2004, Curitiba. Anais... Curitiba, 2004.

PECI, A.; ALCADIPANI, R. Demarcação cientifica: uma reflexão crítica. In: ENANPAD, 28., 2004, Curitiba. Anais... Curitiba, 2004.

PINTO, A. L. The Brazilian Institute of Municipal Administration (Ibam): a case study of institution building in Brazil. Tese (Doutorado) Faculty of the School of Public Administration, University of Southern California. 1968.

. A institucionalização organizacional como estratégia de desenvolvimento. Revista de Administração Pública, Rio de Janeiro, v.3, n.1, p,7-25, jan./jun. 1969.

POWELL, W. W. DiMAGGIO, P. J. The Iron Cage revisited: institutional isomorphism and collective rationality in organizational fields. American Sociological Review, p.147-160, Apr. 1983.

(Ed.). The new institutionalism in organizational analysis. Chicago: University of Chicago Press, 1990

PROCHNO, P. Routine assembly: institutionalizing practices in a new setting. In: ENANPAD, 27., 2003, Atibaia. Anais... Atibaia, 2003.

RAMOS, A. G. The new science of organizations: a reconceptualization of the wealth of nations. Toronto: University of Toronto Press, 1981.

VENTURA, E. C. Dinâmica de institucionalização de práticas sociais: estudo do movimento pela responsabilidade social no setor bancário. Projeto de doutorado - Ebape/FGV, Rio de Janeiro, 2004.

VIEIRA, M. M. F. Análise institucional da dinâmica de setores industriais: um estudo de caso sobre desenvolvimento e declínio de um setor industrial específico. 2000. Projeto de pesquisa (Programa Pró-pesquisa) - Ebape/FGV, Rio de Janeiro, 2000.

; CARVALHO, C.A.; SILVA, R. C. Análise institucional da dinâmica de setores industriais: um estudo de caso sobre desenvolvimento e declínio de um setor industrial específico. 2002. Projeto de Pesquisa. Programa Pró-pesquisa. Ebape/FGV, Rio de Janeiro, 2002.

; MISOCZKY, C. Instituições e poder: explorando a possibilidade de transferências conceituais. In: ENEO 1., 2000, Curitiba. Anais... Curitiba, 2000.

ZUCKER, L. The role of institutionalization in cultural persistence. American Sociological Review, v.41, n.5, p.726-43, 1977.

. Institutional theories of organization. Annual Review of Sociology, v.13, p.443-464, 1987. 